tion. There is, however, no known substance which increases the risk of leukaemia in offspring of those exposed. It is also possible that the most heavily exposed workers might inadvertently bring radioactive materials home-for example on contaminated clothing. Some studies have found unusually high concentrations of some radionuclides in the dust of workers' homes, but the extent of this domestic contamination was probably not sufficient to explain the excess of childhood leukaemia near Sellafield. ${ }^{8}$ Another possibility is that internal rather than external radiation exposure is relevant. If workers were internally contaminated with a radionuclide which was concentrated in the urogenital organs or the semen the doses to the germ cell or the fetus could be greater than those recorded on the worker's externally worn dosimeters or film badges. The risk of prostatic cancer has been shown to be increased in some of the most heavily exposed employees of the United Kingdom Atomic Energy Authority and of the Atomic Weapons Establishment, and it has been suggested that some radionuclides may be concentrated in the prostate. ${ }^{+6}$ In both workforces the risk of prostatic cancer was increased more than 10 -fold in the small group of workers with exposures to external radiation of $100 \mathrm{mSv}$ or more, who also had been monitored for possible internal contamination by many different types of radionuclides, including tritium, plutonium, and uranium. ${ }^{+6}$ Information on internal contamination by radionuclides was not available to Smith and Douglas in their analysis of mortality from cancer in the Sellafield workforce ${ }^{5}$ or to Gardner and his colleagues in today's report.

At this stage it is impossible to distinguish between the various pathways of contamination and the causal mechanisms which might explain the findings by Gardner et al. Despite their preliminary nature the implications are sufficiently important to warrant further investigation. Experimental evidence is sparce, and the finding that irradiation of male mice increases the risk of leukaemia in their offspring needs to be replicated. ${ }^{9}$ Case-control studies similar to that of Gardner et $a l$ are already underway near the nuclear plants at Dounreay and at Aldermaston and Burghfield. Those studies are important, but they too are likely to be plagued by small numbers and large confidence intervals around whatever risk estimates are obtained. Other statistically powerful studies need to be devised, therefore, to discover not only more about the children of nuclear workers but also about the workers themselves. The Committee on Medical Aspects of Radiation in the Environment has already recommended cohort studies of nuclear workers' children..$^{2}$ Germ cell mutations can cause retinoblastoma and other childhood disorders, ${ }^{10}$ and if the increased risk of leukaemia is caused by this mechanism then conditions other than leukaemia should also be studied in the offspring of workers. Highly exposed workers also need to be investigated for possible domestic contamination with radionuclides and also for the possibility that radionuclides might be concentrated in the urogenital organs or seminal fluids.

The results reported today are the first of their kind, and the risks described have large uncertainties associated with them. It would be premature to recommend formal changes to radiation protection limits on the basis of this one study; but until the findings from other studies are available workers need to be counselled and those who have not yet completed their families should be advised to avoid high exposures. The nuclear industry and its workforce have a good record for voluntarily limiting exposure and for collaborating with independent researchers in studying the health of the workers. This needs to continue. The more rapidly the mystery of childhood leukaemia near the nuclear plants can be unravelled the more rapidly steps can be taken to prevent it.

VALERIE BERAL Director

Imperial Cancer Research Fund Cancer Epidemiology Unit, Radcliffe Infirmary, Oxford OX2 6HE

\footnotetext{
Independent Advisory Group. Investigation of the possible increased incidence of cancer in West Cumbria. London: HMSO, 1984. (Black report.)

2 Committee on Medical Aspects of Radiation in the Environment. Third Report. Report on the incidence of childhood cancer in the West Berkshire and North Hampshire area, in which are situated the Atomic Weapons Research Establishment, Aldermaston and the Royal Ordnance Factory, Burghfield. London: HMSO, 1989.

3 Committee on Medical Aspects of Radiation in the Environment. Second Report. Investigation of the possible increased incidence of leukaemia in young people near the Dounreay Nuclear Establishment. Caithness, Scotland. London: HMSO, 1988.

4 Beral V, Fraser P, Carpenter L, Booth M, Brown A, Rose G. Mortality of employees of the Atomic Weapons Establishment, 1951-82. Br Med f 1988;297:757-70.

Smith PG, Douglas AJ. Mortality of workers at the Sellafield plant of British Nuclear Fuets. BrMed f 1986;293:845-54.

6 Beral V, Inskip H, Fraser P, Booth M, Coleman D, Rose G. Mortality of employees of the United Kingdom Atomic Energy Authority, 1946-1979. Br Med f 1985;291:440-7.

7 Ishimaru T, Ishimaru M, Mikami M. Leukaemia incidence among individuals exposed in utero, children of atomic bomb survivors and their controls, Hiroshima and Nagasaki, 1945-79. Hiroshima: Radiation Effects Research Foundation, 1981. (RERF Technical Report 11-81.)

Radiation Effects Research Foundation, 1981. (RERF Technical Report 11-81.)
Goddard AJH, Minski MJ, Thornton I, Culbard EBC. Household particulate survey. Radioactivity in house dust in West Cumbria and its significance. London: Department of the Environment, 1986. (DOE Report DOE/RW/8703.)

9 Nomura T. Parental exposure to $\mathrm{X}$ rays and chemicals induces heritable tumours and anomalies in mice. Nature 1982;296:575-7.

10 Knudson AG. Genetics of human cancer. Annu Rev of Genet 1986;20:231-51.
}

\title{
Bovine spongiform encephalopathy
}

\section{The safety of beef has not yet been tested and may not be testable}

The outbreak of bovine spongiform encephalopathy has caused loss to farmers and continuing public anxiety about possible transmission of infection to humans through beef or milk. Histopathological findings and transmission in the laboratory leave no doubt that the disease belongs to the group of diseases - which includes scrapie, kuru, and CreutzfeldtJakob disease - that may be transmitted by unconventional agents. ${ }^{12}$ Bovine spongiform encephalopathy is scrapie in cattle and is almost certainly acquired from infected sheep products in feed. ${ }^{3}$ Similar transmission has occurred in captive deer, ${ }^{4}$ in mink, ${ }^{5}$ and most recently in studies in mice. ${ }^{6}$ The agents and the diseases they can cause have certain characteristics of great importance to the investigation of the present bovine epidemic and its possible consequences.
The agents are extremely persistent and difficult to destroy. Their presence cannot be detected except by evident clinical disease or pathological changes in the brain. The incubation period is long. In man the incubation period after accidental contamination of the brain is about 18 months. ${ }^{7}$ Symptoms of Creutzfeldt-Jakob disease after subcutaneous injections of human growth hormone prepared from pooled cadaveric pituitary glands appeared after a delay of 15 to 20 years. ${ }^{8}$ Occasional cases of kuru, which is believed to be transmitted solely by cannibalism, still occur more than 30 years after this practice was abandoned. ${ }^{9}$ In monkeys the incubation period after oral administration of large amounts of tissue infected with scrapie was $2 \cdot 5$ years. ${ }^{10}$ Bovine spongiform encephalopathy develops in cattle some five years after eating 
suspect feed. ${ }^{11}$ If, therefore, eating infected beef can cause Creutzfeldt-Jakob disease the development of the disease is likely to be greatly delayed.

Creutzfeldt-Jakob disease is rare: its incidence in England and Wales is 0.49 per million. ${ }^{12}$ Although it can be transmitted in the laboratory to several animal species - usually only by intracerebral injection of brain extracts and exceptionally from person to person by iatrogenic accident ${ }^{7}-$ it is by no means established that the disease is naturally infectious. There have been occasional reports of social contact between patients with overt disease ${ }^{13}$ and three instances of CreutzfeldtJakob disease in neuropathology technicians. ${ }^{1+16} \mathrm{~A}$ small casecontrol study showed a remarkable number of "significant" medical, dietary, and other environmental risk factors, ${ }^{17}{ }^{18}$ but none that were examined could be confirmed in a much larger investigation in Britain. ${ }^{12} \mathrm{~A}$ significant excess of CreutzfeldtJakob disease or other dementing illness is found in close relatives of patients with the disease, ${ }^{12}$ but almost all cases are sporadic. No source of infection or route of entry has been confirmed, and no environmental factor has been identified that might convert a normal protein into a destructive prion. ${ }^{19}$

Understandably, great attention has been paid to the possibility that people might acquire Creutzfeldt-Jakob disease from sheep affected by scrapie, particularly from eating brains, and a few suggestive anecdotes. have been reported..$^{20}$ Anyone in Britain who eats meat will have eaten mutton, and a case-control study could not be expected to detect any excess consumption in those with CreutzfeldtJakob disease. Studies of other contacts with sheep or their products have found no differences from controls. ${ }^{12}$ The incidence of Creutzfeldt-Jakob disease in countries where scrapie has never been found ${ }^{212}$ is similar to that in Britain and France, ${ }^{1+}$ where scrapie has been present for many years. Creutzfeldt-Jakob disease may occur in life long vegetarians, ${ }^{23}$ though it must be admitted that until recently cattle were also thought to be in this category. "Mad cow disease" has naturally caused alarm that might have been mitigated by emphasising that we have long been exposed to the equally mad sheep disease without any demonstrable harm.

What then should be done? Research with "slow viruses" cannot possibly yield rapid results. Further attempts will be made to transmit spongiform encephalopathy from beef and milk to laboratory animals, preferably primates, both by intracerebral injection and by oral administration, but such studies will not answer the question of whether any infection present in beef can cross the species barrier to humans.
An answer could be found only by extremely prolonged monitoring of the incidence of Creutzfeldt-Jakob disease. A baseline exists for the years 1980-4 in England and Wales, ${ }^{12}$ but the task is formidable as every suspected case must be seen by a neurologist who is familiar with the disease. A high necropsy rate is essential and would be difficult to sustain. Such monitoring would identify any large increase in incidence but could not detect or exclude occasional instances of transmission from any environmental source. Repeated claims that British beef is entirely safe to eat are very probably true and largely supported by the opinion of the Southwood committee $^{3}$; but such claims are scarcely scientific when the question has not been tested and is, perhaps, untestable.

Retired Professor of Clinical Neurology,

W B MATTHEWS Oxford OX4 4YN

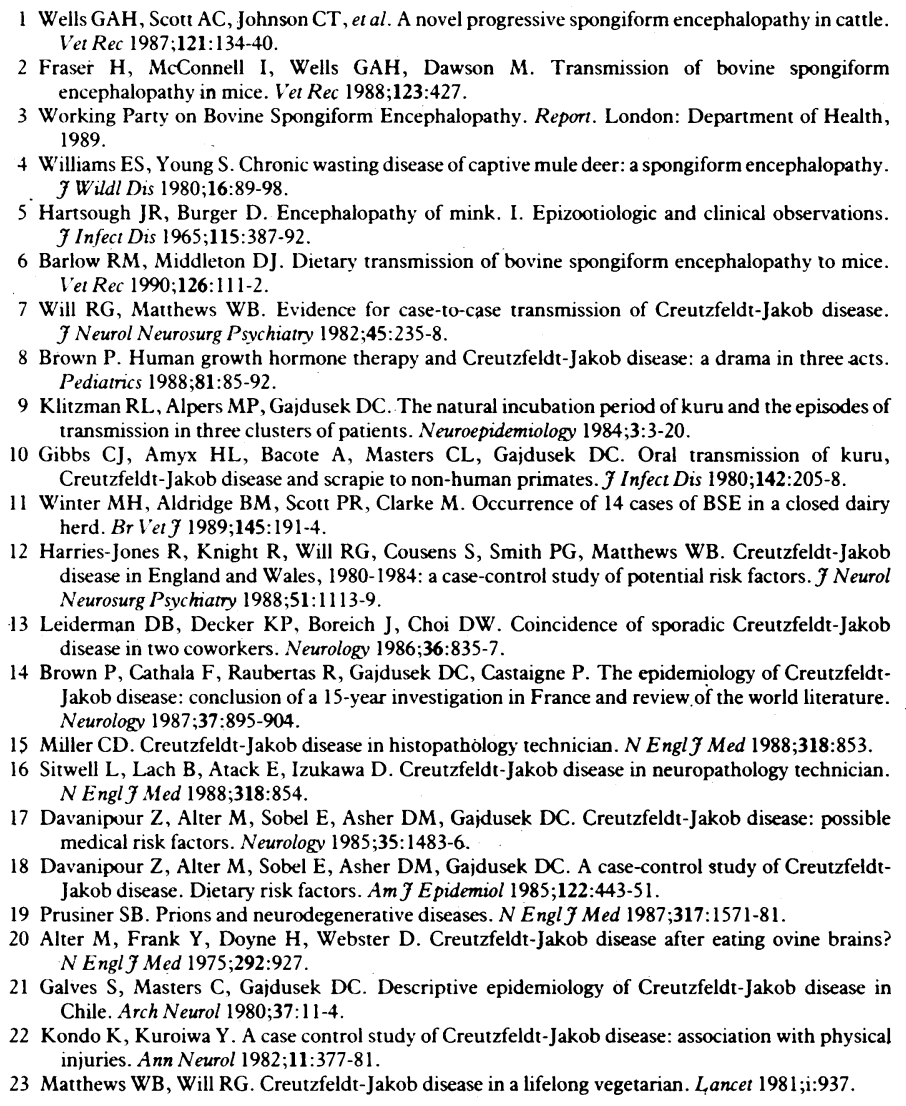

12 Harries-Jones R, Knight R, Will RG, Cousens S, Smith PG, Matthews WB. Creutzfeldt-Jakob disease in England and Wales, 1980-1984: a case-control study of potential risk factors. $\mathcal{F}$ Neurol Neurosurg Psychiatry 1988;51:1113-9.

13 Leiderman DB, Decker KP, Boreich J, Choi DW. Coincidence of sporadic Creutzfeldt-Jakob disease in two coworkers. Neurology 1986;36:835-7.

14 Brown P, Cathala F, Raubertas R, Gajdusek DC, Castaigne P. The epidemiology of CreutzfeldtJakob disease: conclusion of a 15-year investigation in France and review of the world literature. Neurology 1987;37:895-904.

15 Miller CD. Creutzfeldr-Jakob disease in histopathology technician. N Engl f Med 1988;318:853. 16 Sitwell L, Lach B, Atack E, Izukawa D. Creutzfeldt-Jakob disease in neuropathology technician. N Engl F Med 1988;318:854.

17 Davanipour Z, Alter M, Sobel E, Asher DM, Gajdusek DC. Creutzfeldt-Jakob disease: possible medical risk factors. Neurologv 1985;35:1483-6.

18 Davanipour Z, Alter M, Sobel E, Asher DM, Gajdusek DC. A case-control study of CreutzfeldtJakob disease. Dietary risk factors. Am $\mathcal{F}$ Epidemiol 1985;122:443-51.

9 Prusiner SB. Prions and neurodegenerative diseases. $N$ Engl f Med 1987;317:1571-81

20 Alter M, Frank Y, Doyne H, Webster D. Creutzfeldt-Jakob disease after eating ovine brains? Alter M, Frank Y, Doyne H,
N Engl f Med 1975;292:927.

21 Galves S, Masters C, Gajdusek DC. Descriptive epidemiology of Creutzfeldt-Jakob disease in Chile. Arch Neurol 1980;37:11-4

22 Kondo K, Kuroiwa Y. A case control study of Creutzfeldt-Jakob disease: association with physical injuries. Ann Neurol 1982;11:377-81.

23 Matthews WB, Will RG. Creutzfeldt-Jakob disease in a lifelong vegetarian. Lancet 1981;i:937.

\section{The new dermatology}

\section{Improved understanding should yield better treatment}

The recent explosion of knowledge in biomedical science as it relates to the skin offers the possibility of dramatic improvement in our understanding of the aetiology and pathophysiology of important skin diseases - and a possible translation of that understanding into improved diagnosis and treatment.

In non-melanoma skin cancer molecular biological methods are clarifying the part played by specific types of human papillomavirus - 16 and 18 -in squamous carcinoma. Type 16 transforms keratinocytes, but its oncogenicity has been controversial-largely because of differences in the sensitivity of the detection techniques used. ${ }^{12}$ The application of the polymerase chain reaction technique should, however, establish to what extent DNA from human papillomavirus 16 and its subtypes becomes integrated into the cell genome in normal healthy epidermis and in invasive lesions.

More efforts are being directed towards prevention of skin cancer. Sunscreens may be of limited value because they fail to block the immunosuppressive effect of ultraviolet radiation. ${ }^{3}$ It may prove possible to reverse the mutagenic dimerisation of DNA induced by ultraviolet radiation by using a DNA repair endonuclease derived from viral sources. The first recipients of this treatment might be patients with xeroderma pigmentosum (who have a hereditary deficiency of 